\title{
Association of helicobacter pylori infection and chronic atrophic gastritis with risk of colonic, pancreatic and gastric cancer: A ten-year follow-up of the ESTHER cohort study
}

\author{
Xin-Zu Chen ${ }^{1,2, *}$, Ben Schöttker ${ }^{2, *}$, Felipe Andres Castro ${ }^{2}$, Hongda Chen ${ }^{2}$, Yan \\ Zhang ${ }^{2}$, Bernd Holleczek ${ }^{2,3}$, Hermann Brenner ${ }^{2,4}$ \\ ${ }^{1}$ Department of Gastrointestinal Surgery, West China Hospital, Sichuan University, Chengdu, China \\ ${ }^{2}$ Division of Clinical Epidemiology and Aging Research, German Cancer Research Center (DKFZ), Heidelberg, Germany \\ ${ }^{3}$ Saarland Cancer Registry, Saarbrücken, Germany \\ ${ }^{4}$ German Cancer Consortium (DKTK), Heidelberg, Germany \\ *These authors contributed equally to this work
}

Correspondence to: Hermann Brenner, e-mail: h.brenner@dkfz.de

Keywords: helicobacter pylori, chronic atrophic gastritis, colon cancer, pancreatic cancer, gastric cancer

Received: November 21, 2015

Accepted: February 09, 2016

Published: March 06, 2016

\section{ABSTRACT}

Objectives: To assess the association of $\boldsymbol{H}$. pylori and chronic atrophic gastritis (AG) with colonic, pancreatic and gastric cancer in a population-based prospective cohort.

Methods: Serum antibodies against $\boldsymbol{H}$. pylori in general and specific to cytotoxinassociated gene A (CagA), as well as serum pepsinogen I and II were analyzed in 9,506 men and women, aged 50-75 years in a cohort study from Saarland, Germany. Incident cases of colonic, pancreatic and gastric cancer were ascertained by record linkage with data from the Saarland Cancer Registry.

Results: During an average follow-up of 10.6 years, 108 colonic, 46 pancreatic and 27 gastric incident cancers were recorded. There was no association between $H$. pylori infection and colonic cancer $(H R=1.07 ; 95 \%$ CI $0.73-1.56)$ or pancreatic cancer (HR = 1.32; 0.73-2.39), regardless of either CagA seropositivity or AG status. In contrast, CagA+ infection was associated with a strongly increased risk of gastric cancer, especially non-cardia gastric cancer, and this association was particularly pronounced in the presence of AG. Compared to people without AG and without CagA+ infection, people with both risk factors had a significantly increased risk of non-cardia gastric cancer $(H R=32.4 ; 7.6-137.6)$.

Conclusions: This large cohort study did not observe an association of $\boldsymbol{H}$. pylori infection or AG with colonic or pancreatic cancer, but underlines that the vast majority of non-cardia gastric cancers arise from AG and infection with CagA+H. pylori strains.

\section{INTRODUCTION}

Helicobacter pylori (H. pylori) is well-known as a carcinogenic pathogen for gastric cancer [1]. Moreover, H. pylori infection has been suggested to be associated with other cancers of the digestive tract including colonic and pancreatic cancer [2-4], but results were inconclusive. $[5,6]$ To our knowledge, no previous cohort study has simultaneously assessed the risk of various gastrointestinal cancers in the same study population.
Furthermore, H. pylori infection shows a strong association with chronic atrophic gastritis (AG), which is considered as a precancerous lesion of the gastric mucosa [7]. H. pylori infection is likely to be primarily involved in the early stage of development of AG, and less so in the development of gastric cancer from AG [8]. In fact, clearance of the H. pylori infection may often occur in advanced stages of AG [9].

The 4th European Helicobacter Study Group's Maastricht IV/Florence Consensus Report stated that the 
combination of $H$. pylori infection and AG determined by serological examination is suiTable for the identification of subjects with a high risk of gastric cancer [10]. The European Helicobacter Study Group recommends that differences in $H$. pylori virulence factors shall be taken into account to identify subjects with high risk of gastric cancer because the oncogenic potential of $H$. pylori infections strongly varies according to the presence of virulent strains [10]. For example, the cytotoxin-associated gene A (CagA) strain is thought to contribute to cancer development by steps from inflammation to atrophy and then cancer [11-13].

However, data are scarce on the joint prediction of gastric cancer risk by both $H$. pylori infection and presence of $\mathrm{AG}$ while taking major virulence factors into account. Such data are crucial to estimate the potential of serological screen and treat strategies ahead of their implementation. In this article, we report such results from a large population-based cohort study from Germany, paying attention not only to gastric cancer but also to colonic and pancreatic cancer.

\section{RESULTS}

The prevalences of overall (IgG+/anyCagA), CagAand $\mathrm{CagA}+H$. pylori infection at baseline were $49.9 \%$, $22.4 \%$, and $27.5 \%$, respectively. Compared with noninfected participants, $H$. pylori infected participants were older $(p<0.001)$, had lower education levels $(p<0.001)$ and reported to consume less tobacco $(p=0.030)$ and alcohol $(p<0.001)$ (Table 1). Among H. pylori infected persons, those with CagA + strains included slightly higher proportions of females $(p=0.019)$ and never smokers $(p=0.002)$ than those with CagA-strains.

During a median follow-up of 10.6 years, 27 gastric, 108 colonic and 46 pancreatic incident cancers were recorded, respectively (Table 2). Crude incidence rates were $26.97,108.94$ and 45.96 per 100,000 person-years for gastric, colonic and pancreatic cancer, respectively. Participants with $H$. pylori infection had much higher incidence of gastric cancer than non-infected participants, whereas no such pattern was seen for colonic or pancreatic cancer (Figure 1). Furthermore, gastric cancer incidence was much higher among participants infected with CagA+ H. pylori strains than among those infected with CagA$H$. pylori strains. Nevertheless, even among those with $\mathrm{CagA}+H$. pylori infection, gastric cancer incidence was still lower than colonic cancer incidence.

In Cox regression models, very strong associations of $H$. pylori infection were found with gastric cancer (adjusted hazard ratios [95\% CIs] for any and CagA $+H$. pylori infection: 3.91 [1.48-10.38] and 6.27 [2.33-16.86], respectively), but not with the other gastrointestinal cancers (Table 2, Figure 2).

As shown in Table 3, serological evidence of AG was associated with an increased risk of gastric cancer
$(\mathrm{HR}=3.45,95 \%$ CI 1.38-8.64), and CagA + H. pylori infection was associated with a strongly increased risk of gastric cancer regardless of serological evidence of AG.

Even stronger associations were observed when the analyses were restricted to non-cardia gastric cancer, and the risk was particularly high in the presence of both AG and CagA + H. pylori infection (Table 4). Compared to people without AG and without CagA positive infection, people with both risk factors had a 32.4-fold risk of noncardia gastric cancer (95\% CI 7.6-137.6).

No association between $\mathrm{AG}$ and risk of colonic or pancreatic cancer was found (Table 5).

\section{DISCUSSION}

To our knowledge, this is the first study that simultaneously assessed the associations of $H$. pylori infection and AG with gastric, colonic and pancreatic cancer in the same study population. We did not find any association of $H$. pylori infection or AG with colonic or pancreatic cancer. In contrast, very strong associations were found with gastric cancer, especially non-cardia gastric cancer. Participants with serological evidence of both $\mathrm{AG}$ and $\mathrm{CagA}+H$. pylori infection had a 32-fold risk of non-cardia gastric cancer compared to participants with neither of these conditions.

Our study confirms the strong association between $H$. pylori infection and gastric cancer development reported in previous cohort studies from high incidence countries with high prevalence of $H$. pylori infection, such as Japan, Korea and China [13-16]. AmongWestern populations, previous observational studies also identified $H$. pylori as a risk factor for gastric cancer, but few had a prospective cohort design [17-19]. In a meta-analysis of epidemiological studies published until June 2009, it remained unclear whether additional stratification by virulent $H$. pylori strains has an additional benefit in identification of those with the highest risk for gastric cancer [20]. Our study agrees with another large prospective cohort study published after the review that risk stratification by virulence factors is indeed important [21]. In our study, we found that participants infected with non-virulent strains $(\mathrm{CagA}-)$ did not have an increased risk of developing gastric cancer, whereas those infected with virulent strains $(\mathrm{CagA}+)$ did. Among many $H$. pylori specific proteins, it is widely acknowledged that CagA, generated from virulent strains, induces extensive inflammation and progression to more severe disease states [22]. Therefore, if $H$. pylori testing is carried out, the serological CagA status should also be determined to better judge the gastric cancer risk. Furthermore, previous studies showed that $H$. pylori infection might be related to gastric cancer through its influence on the onset and progression of AG $[13,23]$. A previous longitudinal analysis of the ESTHER study showed that infection with $H$. pylori was a strong predictor for the development of AG [24]. In particular, study participants with infection of virulent 
Table 1: Characteristics of population by $\mathrm{H}$. pylori infectionand CagA seropositivityat baseline

\begin{tabular}{|c|c|c|c|c|c|c|c|}
\hline \multirow{3}{*}{ Characteristics } & \multirow{3}{*}{ Total } & \multirow{2}{*}{$\frac{\text { Non-infected }}{\text { IgG-/CagA- }}$} & \multicolumn{3}{|c|}{ H. pylori infected } & \multirow{3}{*}{$\begin{array}{c}P \text { value } \\
\dagger\end{array}$} & \multirow{3}{*}{$\begin{array}{c}P \text { value } \\
t\end{array}$} \\
\hline & & & $\begin{array}{c}\text { IgG+/any } \\
\text { CagA }\end{array}$ & IgG+/CagA- & IgG $+/$ CagA + & & \\
\hline & & $n(\%)$ & $n(\%)$ & $n(\%)$ & $n(\%)$ & & \\
\hline Observations $(n)$ & 9,506 & 4,767 & 4,739 & 2,128 & 2,611 & & \\
\hline Prevalence & & - & $49.9 \%$ & $22.4 \%$ & $27.5 \%$ & & \\
\hline Age (years) & & & & & & $<0.001$ & 0.562 \\
\hline $50-54$ & 1,627 & $925(19.4)$ & $702(14.8)$ & $322(15.1)$ & $380(14.6)$ & & \\
\hline $55-59$ & 1,616 & $922(19.3)$ & $694(14.6)$ & $321(15.1)$ & $373(14.3)$ & & \\
\hline $60-64$ & 2,590 & $1,285(27.0)$ & $1,305(27.5)$ & $580(27.3)$ & $725(27.8)$ & & \\
\hline $65-69$ & 2,176 & 998 (20.9) & $1,178(24.9)$ & $512(24.1)$ & $666(25.5)$ & & \\
\hline $70-75$ & 1,497 & $637(13.4)$ & $860(18.2)$ & $393(18.5)$ & $467(17.9)$ & & \\
\hline Sex & & & & & & 0.438 & 0.019 \\
\hline Female & 5,215 & $2,634(55.3)$ & $2,581(54.5)$ & $1,119(52.6)$ & $1,462(56.0)$ & & \\
\hline Male & 4,291 & $2,133(44.7)$ & $2,158(45.5)$ & $1,009(47.4)$ & $1,149(44.0)$ & & \\
\hline Education (years) & & & & & & $<0.001$ & 0.703 \\
\hline$\leq 9$ & 6,933 & $3,339(71.5)$ & $3,594(78.2)$ & $1,620(78.4)$ & $1,974(78.1)$ & & \\
\hline $10-11$ & 1,302 & $738(15.8)$ & $564(12.3)$ & $259(12.5)$ & $305(12.1)$ & & \\
\hline$\geq 12$ & 1,030 & $594(12.7)$ & $436(9.5)$ & $187(9.1)$ & $249(9.9)$ & & \\
\hline Smoking status & & & & & & $\mathbf{0 . 0 3 0}$ & 0.002 \\
\hline Never & 4,623 & $2,277(48.9)$ & $2,346(51.2)$ & $1,004(48.5)$ & $1,342(53.3)$ & & \\
\hline Former & 3,049 & $1,567(33.6)$ & $1,482(32.3)$ & $705(34.1)$ & 777 (30.9) & & \\
\hline Current & 1,571 & $814(17.5)$ & $757(16.5)$ & $359(17.4)$ & $398(15.8)$ & & \\
\hline Alcohol consumption & & & & & & $<0.001$ & 0.187 \\
\hline Abstainer & 2,792 & $1,315(30.2)$ & $1,477(34.9)$ & $644(33.7)$ & $833(35.8)$ & & \\
\hline $\begin{array}{l}\text { Women } 0-19.99 \mathrm{~g} / \mathrm{d} \\
\text { or Men } 0-39.99 \mathrm{~g} / \mathrm{d}\end{array}$ & 5,200 & $2,697(62.0)$ & $2,503(59.1)$ & $1,150(60.2)$ & $1,353(58.2)$ & & \\
\hline $\begin{array}{l}\text { Women } \\
\geq 20 \mathrm{~g} / \mathrm{d} \\
\text { or Men } \geq 40 \mathrm{~g} / \mathrm{d}\end{array}$ & 591 & $338(7.8)$ & $253(6.0)$ & $115(6.0)$ & 138 (5.9) & & \\
\hline
\end{tabular}

Abbreviations: CagA, cytotoxin-associated gene A; IgG, immunoglobulin G; H. pylori, Helicobacter pylori.

${ }^{\dagger} P$ value, for comparison between non-infected (IgG-/CagA-) participants and all $H$. pylori infected (IgG+/any CagA) participants.

${ }_{\sharp} P$ value, for comparison between participants with $\mathrm{IgG}+/ \mathrm{CagA}+$ and $\mathrm{IgG}+/ \mathrm{CagA}-H$. pylori infection.

strains $(\mathrm{CagA}+)$ had a strongly increased incidence of AG. The current study extends this finding by showing a dramatically increased risk of non-cardia gastric cancer in the presence of both $\mathrm{AG}$ and $\mathrm{CagA}+H$. pylori infection.

In the light of these results from epidemiological studies, H. pylori eradication is highly likely and effective approach for gastric cancer prevention. However, the evidence from randomized controlled trials (RCTs) was very sparse until the so far largest study recently published updated results with 15 -year follow-up data $[25,26]$. The result of this Chinese study has recently been metaanalyzed with the five other RCTs conducted in middle and late adulthood so far [27]. In summary, gastric cancer risk was statistically significantly reduced by $36 \%$ by $H$. pylori eradication. Given that $H$. pylori is mostly acquired in childhood even stronger reduction of gastric cancer risk 
Table 2: Incidence and risk of gastric, colonic and pancreatic cancer by $\boldsymbol{H}$. pylori infection and CagA seropositivity

\begin{tabular}{|c|c|c|c|c|c|}
\hline \multirow{2}{*}{ Cancers } & \multirow{2}{*}{ Total } & \multirow{2}{*}{$\frac{\text { Non-infected }}{\text { IgG-/CagA- }}$} & \multicolumn{3}{|c|}{ H. pylori infected } \\
\hline & & & IgG+/any CagA & IgG+/CagA- & IgG+/CagA+ \\
\hline $\begin{array}{c}\text { Gastric cancer } \\
\text { (observations, } n \text { ) }\end{array}$ & 9,497 & 4,760 & 4,737 & 2,127 & 2,610 \\
\hline Cases $(n)$ & 27 & 5 & 22 & 3 & 19 \\
\hline Crude incidence rate $\dagger$ & 26.97 & 9.96 & 44.08 & 13.32 & 69.37 \\
\hline $\mathrm{HR}_{1}(95 \% \mathrm{CI}) \dagger$ & - & Ref & $3.91(1.48-10.38)$ & $1.16(0.28-4.86)$ & $6.27(2.33-16.86)$ \\
\hline $\mathrm{HR}_{2}(95 \% \mathrm{CI})+$ & - & - & - & Ref & 5.57 (1.64-18.89) \\
\hline $\begin{array}{c}\text { Colonic cancer } \\
\text { (observations, } n \text { ) }\end{array}$ & 9,443 & 4,733 & 4,710 & 2,120 & 2,590 \\
\hline Cases $(n)$ & 108 & 50 & 58 & 32 & 26 \\
\hline Crude incidence rate $\dagger$ & 108.94 & 100.61 & 117.32 & 143.55 & 95.78 \\
\hline $\mathrm{HR}_{1}(95 \% \mathrm{CI})+$ & - & Ref & $1.07(0.73-1.56)$ & $1.30(0.83-2.03)$ & $0.87(0.54-1.14)$ \\
\hline $\mathrm{HR}_{2}(95 \% \mathrm{CI}) \dagger$ & - & - & - & Ref & $0.68(0.40-1.14)$ \\
\hline $\begin{array}{c}\text { Pancreatic cancer } \\
\text { (observations, } n \text { ) }\end{array}$ & 9,504 & 4,766 & 4,738 & 2,128 & 2,610 \\
\hline Cases $(n)$ & 46 & 19 & 27 & 15 & 12 \\
\hline Crude incidence rate $\dagger$ & 45.96 & 37.86 & 54.11 & 66.78 & 43.74 \\
\hline $\mathrm{HR}_{1}(95 \% \mathrm{CI}) \dagger$ & - & Ref & $1.32(0.73-2.39)$ & $1.61(0.82-3.18)$ & $1.08(0.52-2.24)$ \\
\hline $\mathrm{HR}_{2}(95 \% \mathrm{CI})+$ & - & - & - & Ref & $0.67(0.31-1.43)$ \\
\hline
\end{tabular}

Abbreviations: CagA, cytotoxin-associated gene A; CI, confidence interval; IgG, immunoglobulin G; H. pylori, Helicobacter pylori; HR, hazard ratio.

"Per 100,000 person-years.

*Adjusted for age, sex, education level, smoking status and alcohol consumption. $\mathrm{HR}_{1}$, comparing infected (IgG+) and noninfected (IgG-/CagA-) participants. $\mathrm{HR}_{2}$, comparing participants with $\operatorname{IgG}+/ \mathrm{CagA}+$ and $\operatorname{IgG}+/ \mathrm{CagA}-$ H. pylori infection.

might be achieved by eradication earlier in life, but this will be difficult to demonstrate by clinical trials which would take decades to complete.

Our study underlines that the vast majority of gastric cancers arise from AG and infection with CagA+ H. pylori strains. These two high-risk groups should undergo different further treatment. The European Helicobacter Study Group agreed on the following statement "Serological screening is suitable for clinical use in countries with a relatively low incidence of gastric cancer, because it enables endoscopic follow-up of cases with an abnormal serological profile suggesting atrophic gastritis" [10, 28]. Endoscopy enables the detection and resection of early malignancies and has a high potential to prevent gastric cancer mortality in AG patients [29]. Eradication treatment of $H$. pylori infection among patients with any premalignant lesions is recommended by all major international guidelines [30]. Our study results imply that additionally, all participants free of AG but with CagA positive $H$. pylori infection are high-risk patients and should receive eradication treatment. A cost-effectiveness study estimated that screening for and treatment of CagA $+H$. pylori strains has a similar cost-effectiveness compared to screening for and treating of all $H$. pylori infected individuals in the United States, Finland, Columbia, Japan and countries with similar $H$. pylori prevalence and gastric cancer incidence [31]. The limitations of the cited study were that it did not include screening for $\mathrm{AG}$ and did not consider potential negative effects by antibiotic treatment. Cost-effectiveness of a combined serological screening and treatment study for $\mathrm{AG}$ and $\mathrm{CagA}+H$. pylori infection will likely be higher because more premalignant cancers would be detected among AG patients and fewer individuals with low gastric cancer risk (H. pylori+/CagA- individuals) would receive antibiotic treatment reducing the risk for adverse events and resistant bacteria. However, currently no organized screening programs exist outside the high-risk countries Japan and South Korea [32]. 
Colonic cancer has also been linked to $H$. pylori infection by previous studies. A recent meta-analysis summarized 17 case-control studies for the outcome colon cancer and 16 for the outcome colon polyps and obtained modest but statistically significant associations of $H$. pylori infection with both outcomes [33]. However, only three studies had a prospective design and all three studies did not observe an association of $H$. pylori infection with colonic canceror colon polyps [34-36]. Our prospective cohort study does support the findings of the previous prospective studies and extends their results by adding that stratification by CagA seropositivity or AG also did not lead to the observation of an association of $\mathrm{H}$. pylori infection with colon cancer incidence.

Likewise, inconsistent results for an association between $H$. pylori infection and pancreatic cancer have been reported although the recent review of Xiao et al. [6]. did not observe heterogeneity across 9 included studies and reporting strong effect estimates from metaanalysis. However, comparing the 3 prospective nested case-control studies reveals that only one study from Finland observed a significant association between H. pylori infection and $\mathrm{CagA}+$ with pancreatic cancer, whereas other studies from Sweden and the United states did not observe this association [37-39]. Our study results are in agreement with the latter studies that do not support a major etiological role of $H$. pylori in pancreatic cancer development. Interestingly, a recent meta-analysis based on five prospective nested case-controlstudies found the infection with CagA-negative non-virulent $H$. pylori might be associated with increased risk of pancreatic cancer development [40]. In summary, current study results about the association of $H$. pylori infection and pancreatic cancer are conflicting and further prospective, ideally larger studies are required to assess whether $\mathrm{H}$. pylori infection is associated with pancreatic cancer.
There are some limitations of our study that should be kept in mind when interpreting our results. First, in our study with 10 years of follow-up, only 27 incident gastric cancers occurred, which precluded more detailed analysis, e.g. by sex or major age groups. However, the associations of $\mathrm{AG}$ and $\mathrm{CagA}+H$. pylori infection with gastric cancer incidence were so strong that they were highly statistically significant despite the small case number. Nevertheless, the confidence intervals are wide and the strength of the observed associations could not be estimated with high precision. Second, we did not assess other important virulent factors, such as vacuolating cytotoxin $\mathrm{A}$ (VacA), helicobacter cysteine-rich protein $\mathrm{C}$ ( $\mathrm{HcpC})$, and chaperonin (GroEL), which might be informative in addition to CagA. Those virulent proteins of $H$. pylori were previously found to be potential risk factors associated with AG, gastric cancer, or colonic cancer [41-43]. Finally, information on eradication treatment for $H$. pylori infection after baseline was not available, which could have influenced our findings.

In summary, we did not observe an association between $H$. pylori infection as well as AG with colonic or pancreatic cancer in this population-based prospective study which does not support suggestions from previous case-control studies that $H$. pylori infection increases extragastric malignancy risk. On the contrary, our study underlines that the vast majority of non-cardia gastric cancers arise from $\mathrm{AG}$ and infection with $\mathrm{Cag} \mathrm{A}+H$. pylori strains. These study results underline that subjects with $\mathrm{AG}$ and $\mathrm{CagA}+$ H. pylori infection are at high risk for gastric cancer and screening programs should focus on the identification and treatment of these two groups. Further studies are needed to evaluate the feasibility, potential for adverse conditions and cost-effectiveness of such a targeted screening and eradication program in Western populations with low to intermediate gastric cancer risk.

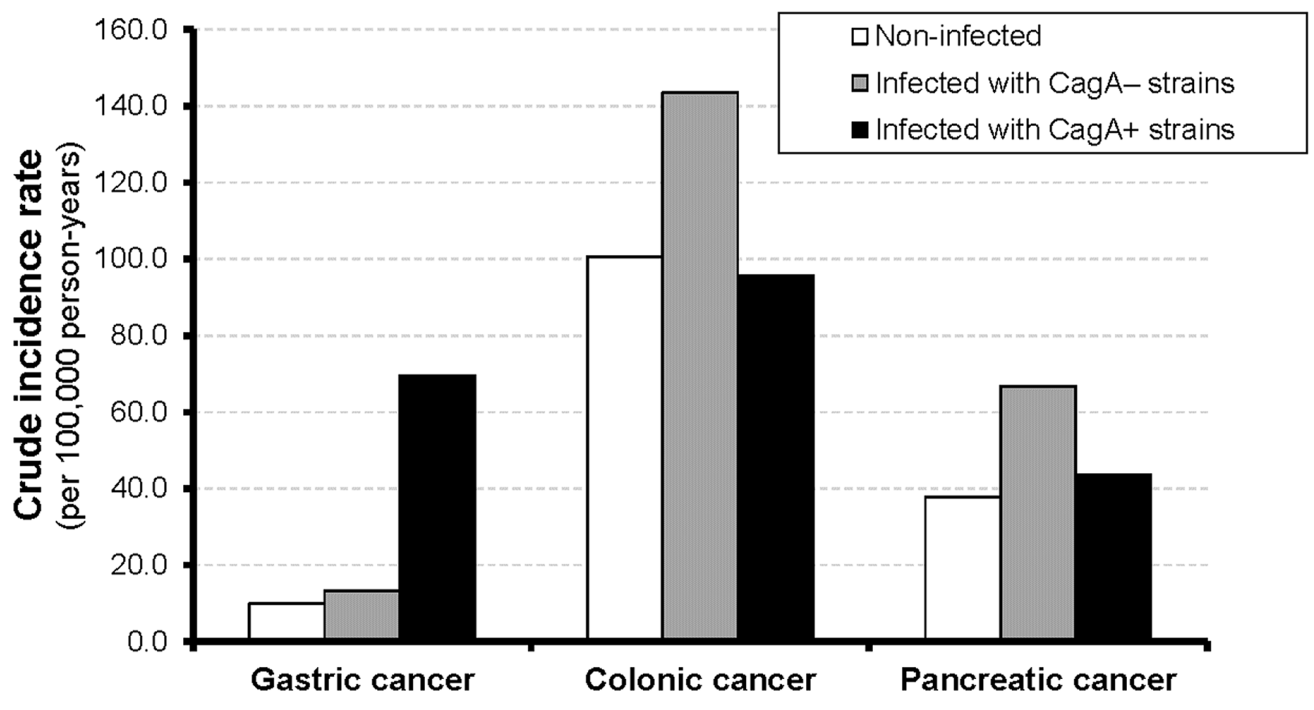

Figure 1: Crude incidence rate (per 100,000 person-years) of gastric, colonic and pancreatic cancer by $\mathrm{H}$. pylori infection and CagA serostatus at baseline. 


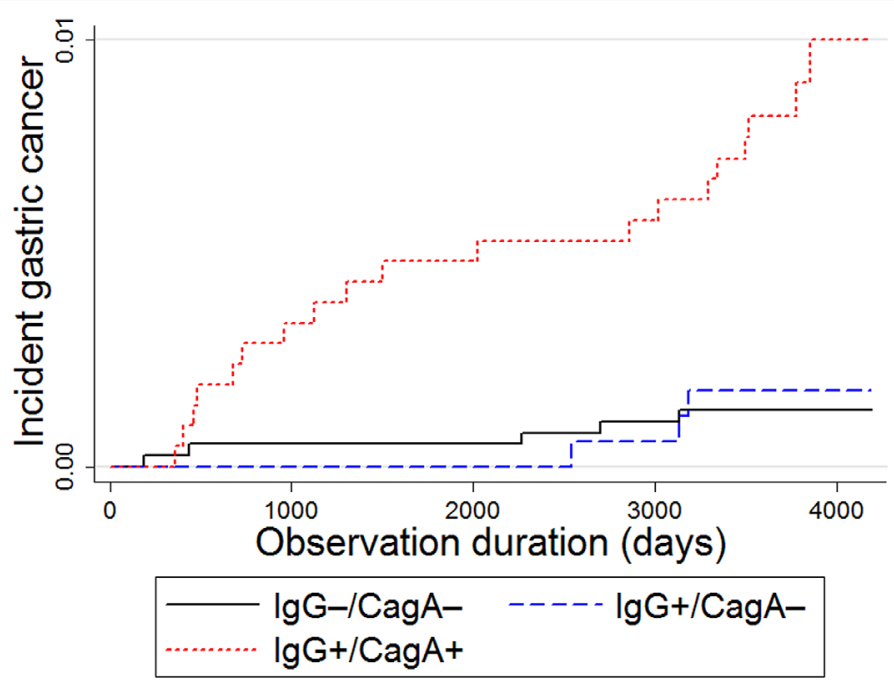

(A)

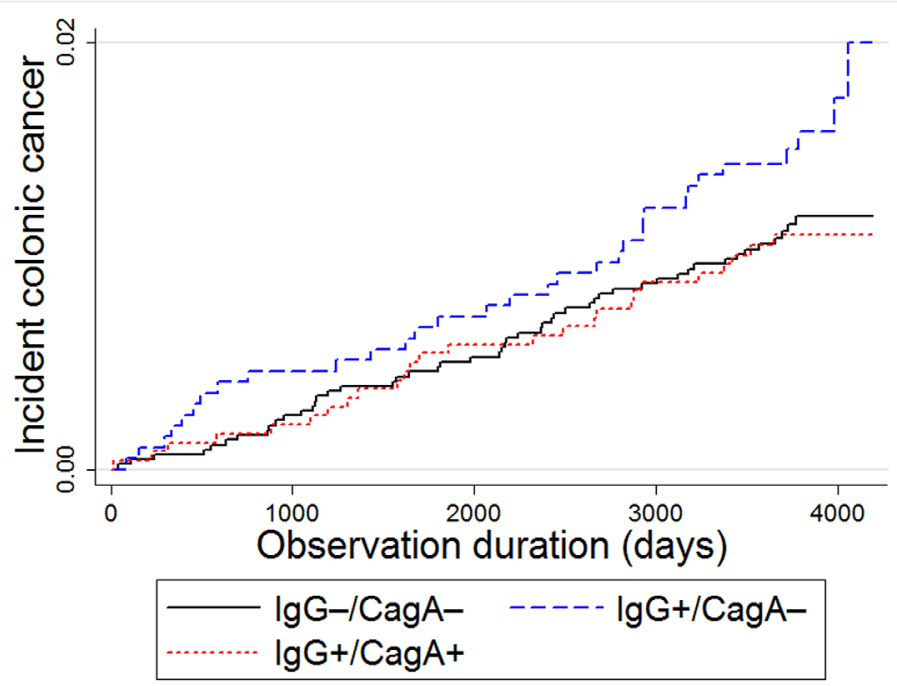

(B)

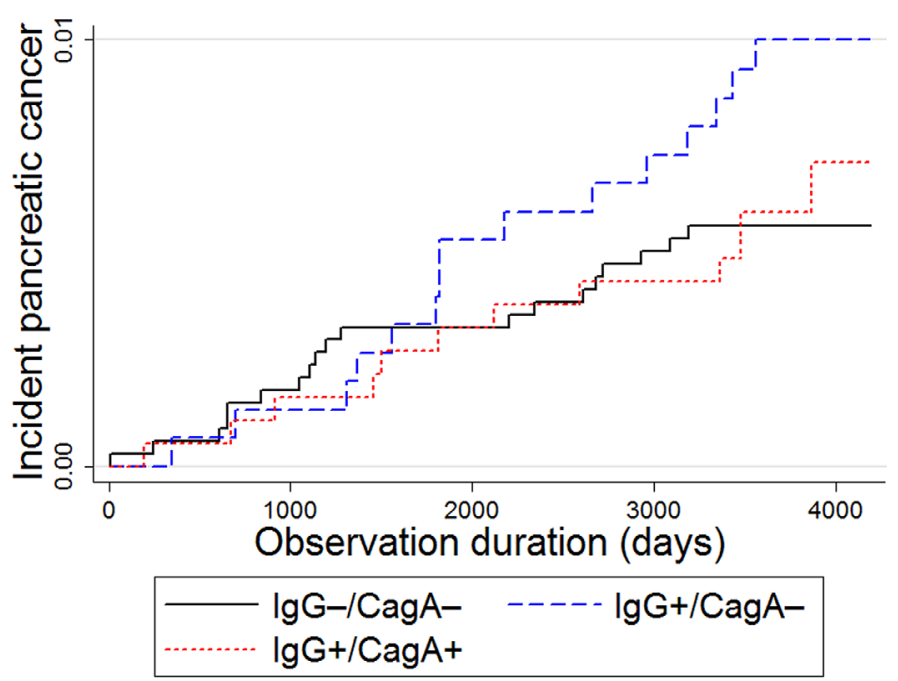

(C)

Figure 2: Incidence of cancer by $\boldsymbol{H}$. pylori IgG and CagA serostatus. Kaplan-Meier curves and Log-rank test of the incidence of (A) gastric, (B) colonic and (C) pancreatic cancer. Significant differences were observed for gastric cancer incidence in comparisons of virulent strains to non-infected ( $p<0.0001)$, and virulent strains to non-virulent strains $(p=0.003)$, but not in non-virulent strains to noninfected $(p=0.686)$. No significant differences were observed for colonic and pancreatic cancer incidence $(p>0.05)$. 
Table 3: Risk of gastric cancer incidence by chronic atrophic gastritis, $H$. pylori infection and CagA seropositivity

\begin{tabular}{|c|c|c|c|c|c|c|}
\hline $\begin{array}{l}\text { Chronic atrophic } \\
\text { gastritis }\end{array}$ & $\begin{array}{l}\text { H. pylori } \\
\text { infection }\end{array}$ & $\begin{array}{l}\text { Sample } \\
(n)\end{array}$ & $\begin{array}{c}\text { Cases } \\
(n)\end{array}$ & $\begin{array}{c}\text { Crude } \\
\text { incidence rate } \dagger\end{array}$ & $\mathrm{HR}_{1}(95 \% \mathrm{CI})$ & $\mathrm{HR}_{2}(95 \% \mathrm{CI})+$ \\
\hline None & IgG-/CagA- & 4,555 & 5 & 10.42 & \multirow{3}{*}{ Ref } & Ref \\
\hline & $\mathrm{IgG}+/ \mathrm{CagA}-$ & 1,984 & 2 & 9.54 & & $0.79(0.15-4.08)$ \\
\hline & $\mathrm{IgG}+/ \mathrm{Cag} \mathrm{A}^{+}$ & 2,295 & 14 & 58.13 & & $5.05(1.81-14.09)$ \\
\hline \multirow[t]{3}{*}{ Present } & IgG-/CagA- & 205 & 0 & 0 & \multirow{3}{*}{$3.45(1.38-8.64)$} & Not estimable \\
\hline & $\mathrm{IgG}+/ \mathrm{CagA}-$ & 143 & 1 & 64.61 & & $5.50(0.63-47.57)$ \\
\hline & $\mathrm{IgG}+/ \mathrm{CagA}+$ & 315 & 5 & 151.20 & & $12.51(3.57-43.22)$ \\
\hline
\end{tabular}

Abbreviations: CagA, cytotoxin-associated gene A; CI, confidence interval; H. pylori, Helicobacter pylori; HR, hazard ratio. "Per 100,000 person-years.

${ }^{\sharp}$ Adjusted for age, sex, education level, smoking status and alcohol consumption. $\mathrm{HR}_{1}$, comparing participants with and without chronic atrophic gastritis. $\mathrm{HR}_{2}$, comparing different groups with participants without chronic atrophic gastritis and without $H$. pylori infection.

Table 4: Risk of developing non-cardia gastric cancer by chronic atrophic gastritis, $H$. pylori infection and CagA seropositivity

\begin{tabular}{|c|c|c|c|c|c|}
\hline $\begin{array}{l}\text { Chronic atrophic } \\
\text { gastritis }\end{array}$ & H. pylori infection & Sample $(n)$ & $\begin{array}{c}\text { Cases } \\
(n)\end{array}$ & $\begin{array}{c}\text { Crude incidence } \\
\text { rate } \dagger\end{array}$ & $\operatorname{HR}(95 \% \mathrm{CI}) \ddagger$ \\
\hline Any & IgG-/CagA-, or IgG $+/ \mathrm{CagA}-$ & 6,883 & 4 & 5.50 & Ref \\
\hline Any & $\mathrm{IgG}+/ \mathrm{CagA}+$ & 2,608 & 17 & 62.09 & $18.06(2.42-134.92)$ \\
\hline None & Any & 8,828 & 15 & 16.13 & Ref \\
\hline Present & Any & 663 & 6 & 84.73 & $4.77(1.82-12.49)$ \\
\hline None & IgG-/CagA-, or IgG+/CagA- & 6,535 & 3 & 4.35 & Ref \\
\hline Present & IgG-/CagA-, or IgG $+/ \mathrm{CagA}-$ & 348 & 1 & 26.49 & $5.55(0.57-53.97)$ \\
\hline None & $\operatorname{IgG}+/ \mathrm{Cag} A+$ & 2,293 & 12 & 49.85 & $11.21(3.16-39.84)$ \\
\hline Present & $\mathrm{IgG}+/ \mathrm{Cag} \mathrm{A}+$ & 315 & 5 & 151.20 & $32.39(7.63-137.62)$ \\
\hline
\end{tabular}

Abbreviations: CagA, cytotoxin-associated gene A; CI, confidence interval; H. pylori, Helicobacter pylori; HR, hazard ratio. "Per 100,000 person-years

*Adjusted for age, sex, education level, smoking status and alcohol consumption. 
Table 5: Association between chronic atrophic gastritis and colonic or pancreatic cancer

\begin{tabular}{|c|c|c|c|c|c|}
\hline Cancer & Chronic atrophic gastritis $\dagger$ & Sample (n) & Cases $(n)$ & $\begin{array}{c}\text { Crude incidence } \\
\text { rate }\end{array}$ & HR $(95 \%$ CI $) \S$ \\
\hline \multirow[t]{3}{*}{ Colonic cancer } & None & 8,777 & 99 & 107.58 & Ref \\
\hline & Mild-moderate & 305 & 5 & 153.88 & $1.29(0.52-3.18)$ \\
\hline & Severe & 361 & 4 & 103.52 & $0.81(0.30-2.20)$ \\
\hline \multirow[t]{3}{*}{ Pancreatic cancer } & None & 8,835 & 42 & 45.20 & Ref \\
\hline & Mild-moderate & 307 & 2 & 60.89 & $1.32(0.32-5.49)$ \\
\hline & Severe & 362 & 2 & 51.63 & $1.09(0.26-4.52)$ \\
\hline
\end{tabular}

Abbreviations: CI, confidence interval; HR, hazard ratio.

'Mild-moderate and severe $\mathrm{AG}$ are defined as serostatus: (i) $20 \mathrm{ng} / \mathrm{mL} \leq$ pepsinogen (PG) I $<70 \mathrm{ng} / \mathrm{mL}$ and PG I/II ratio $<3.0$, and (ii) $\mathrm{PG}<20 \mathrm{ng} / \mathrm{mL}$ and $\mathrm{PG} \mathrm{I} / \mathrm{II}$ ratio $<3.0$ ), respectively [48].

Per 100,000 person-years.

$\S$ Adjusted for age, sex, education level, smoking status and alcohol consumption.

\section{MATERIALS AND METHODS}

\section{Study design}

The ESTHER study (Epidemiologische Studie zu Chancen der Verhütung, Früherkennung und optimierten Therapie chronischer Erkrankungen in der älteren Bevölkerung [German]) is a population-based prospective cohort study conducted in Saarland, a federal state in the southwest of Germany. A total of 9,949 participants aged 50-75 years were recruited by their general practitioners during a general health check-up between July 2000 and December 2002. Those with insufficient knowledge of the German language were excluded. Details of the study design have been reported elsewhere [44-46].

\section{Ethics}

The study was approved by the ethics committees of the medical faculty of the University of Heidelberg and of the medical board of the German federal state of Saarland. Written informed consent was obtained from each participant.

\section{Data collection}

\section{Questionnaires}

A standardized questionnaire was used to collect comprehensive information on participants' sociodemographic and lifestyle characteristics at baseline. General practitioners completed a standardized health check-up form and provided medical information.

\section{Serologic examinations}

Serum samples were obtained from all participants at baseline and stored at $-80^{\circ} \mathrm{C}$ until analysis. All samples were analyzed by enzyme-linked immunosorbent assay (ELISA) for the presence of immunoglobulin $\mathrm{G}$ (IgG) antibodies both against $H$. pylori in general and specific to the CagA of H. pylori (H. pylori Screening ELISA and $H$. pylori p120 [CagA] ELISA; ravo H. Pylori Diagnostika, Freiburg, Germany). Classification of infection status was performed according to the manufacturer's instructions and borderline results were considered negative. Additionally, serum concentrations of pepsinogen (PG) I and II were determined by ELISA (Biohit, Helsinki, Finland).

Participants were categorized based on their serostatus of $H$. pylori $\mathrm{IgG}$ and CagA, as: (i) noninfected (IgG-/CagA-), (ii) carrying CagA- H. pylori infection ( $\operatorname{IgG}+/ \mathrm{CagA}-)$, and (iii) carrying $\mathrm{CagA}+H$. pylori infection $(\mathrm{IgG}+/ \mathrm{CagA}+)$. For presence of $\mathrm{AG}$, the following commonly employed serological classification was used: PG I $<70 \mathrm{ng} / \mathrm{mL}$ and PG I/II ratio $<3.0$ $[41,47,48]$.

\section{Follow-up}

Follow-up with respect to cancer incidence and mortality was conducted by record linkage with the statewide Saarland Cancer Registry through December 31st, 2011. The completeness of the cancer registry data was further increased by linkage with mortality statistics of the Saarland with collected death certificates of all deceased inhabitants and collecting information on newly developed cancers by questionnaires to the study participants at the 2-, 5- and 8-year follow-up of the ESTHER study (response rates among survivors: $96 \%, 88 \%$ and $79 \%$, respectively). Self-reported cancers were validated by inquiry at the general practitioners of the study participants and only confirmed cases were considered as cases. Cancers specifically addressed in this analysis include gastric cancer (International Classification of Diseases 10th version [ICD-10] code: C16), colonic 
cancer (C18) and pancreatic cancer (C25). For gastric cancer, an additional distinction was made between cardia cancer (C16.0) and non-cardia gastric cancer (all except C16.0 in C16 classification).

\section{Population}

Figure 3 shows the flow chart for the selection of the study population. Participants without measurement of $\mathrm{AG}$ or $H$. pylori infection were excluded. In order to minimize potential misclassification of infection status, we also excluded 203 participants with $\mathrm{IgG}-/ \mathrm{CagA}+$ $H$. pylori serostatus, which might often reflect past infection [49]. Among 9,056 remaining participants, 9, 63 and 2 subjects had a history of gastric, colonic and pancreatic cancer before baseline, respectively, and were excluded from analyses of the incidence of the respective cancer.

\section{Statistical analysis}

General characteristics of the population by H. pylori status were compared by Chi-square test for categorical variables and Wilcoxon test for ranked variables. Univariate time-to-event analyses were performed using Kaplan-Meier curves and log-rank tests were applied to compare incidence among the following groups of participants: non-infected, all infected, infected with non-virulent or with virulent strains. In addition, multivariate analyses were performed by Cox proportional hazards model after checking the proportional hazards assumption by the Kolmogorov-type supremum test based on a sample of 1,000 Martingale residual patterns (no statistically significant violations observed; data not shown), and hazard ratios (HRs) with 95\% confidence intervals (CIs) were estimated. Cox models were adjusted for age, gender, education level, smoking and alcohol

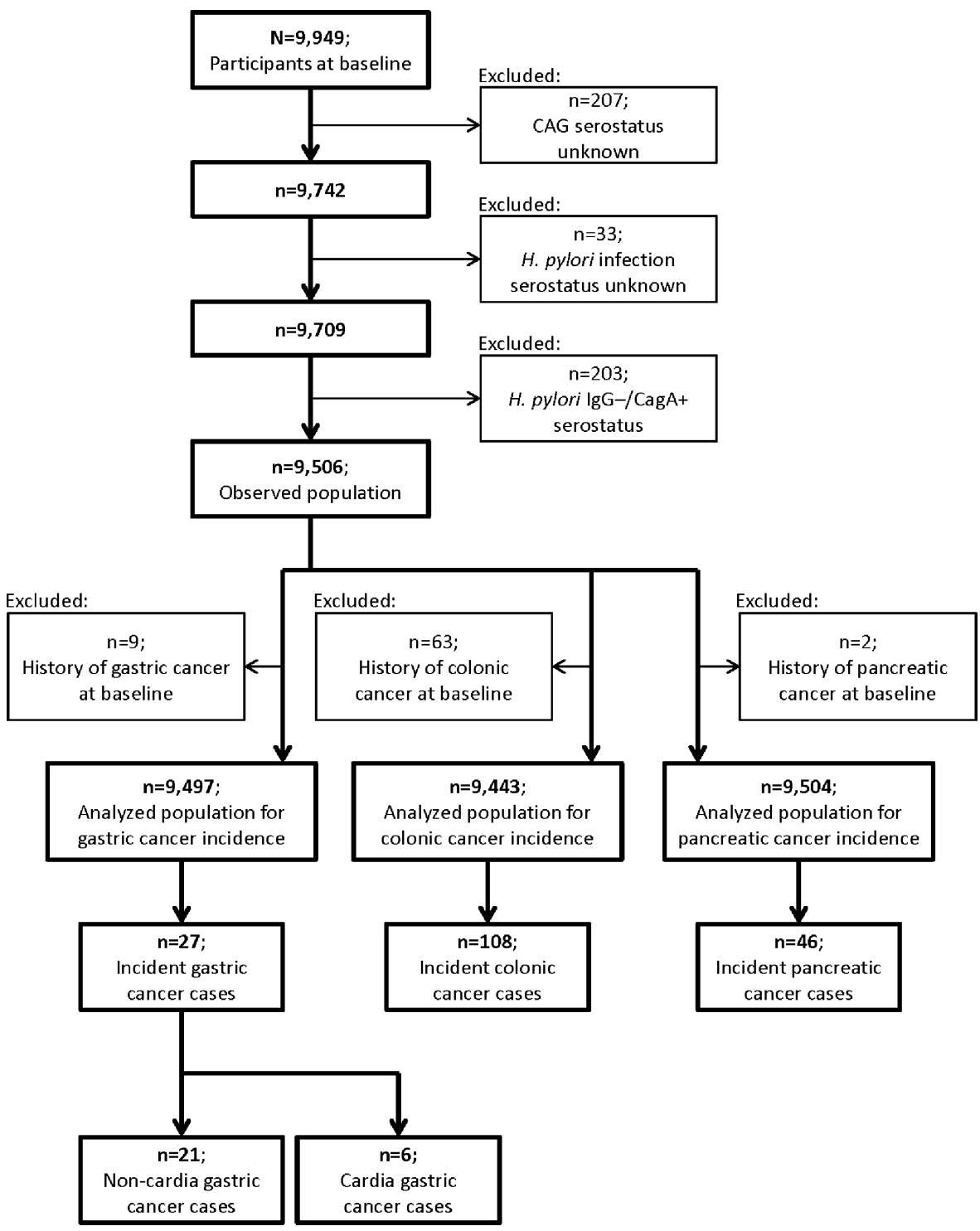

Figure 3: Flow chart for selection of the study population. 
consumption. Cox regression was also used to separately compare the incidence of gastric, colonic and pancreatic cancer between non-atrophic and atrophy-presenting subjects, respectively. Additionally, in analyses for all gastric cancer or non-cardia cancer only, the non-atrophic and atrophy-presenting persons were further stratified by $H$. pylori serostatus. All statistical tests were 2 -sided and statistical significance was defined as $p<0.05$. SAS, version 9.2, statistical software (SAS Institute, Cary, North Carolina) was used for statistical analyses.

Multiple imputation was employed to impute missing values in baseline covariates. Information on age and sex was complete and the proportions of missing values for education, smoking and alcohol consumption were $2.5 \%, 2.8 \%$ and $9.7 \%$, respectively. To the best of our knowledge, data were missing at random, which was the assumption of the multiple imputation. The variables age, sex, education level, smoking and alcohol consumption were used for the imputation model and 20 data sets were imputed with the SAS 9.2 procedure "PROC MI", using the Markov chain Monte Carlo method. All multivariable analyses were performed in the 20 imputed data sets and results of the individual data sets were combined by the SAS 9.2 procedure "PROC MIANALYZE", taking the variation between the results of the imputed data sets into account.

\section{GRANT SUPPORT}

The ESTHER study baseline examination was supported by a grant from the Baden-Württemberg State Ministry of Science, Research and Arts. The work of Dr. Xin-Zu Chen was supported by the National Natural Science Foundation of China (No. 81372344 and No. 81301866).

\section{Authors' contributions}

$\mathrm{XZ} \mathrm{C}$ and $\mathrm{B} \mathrm{S}$ contributed equally as co-first authors. XZ C and $\mathrm{H}$ B concepted the study. B S and B H managed the dataset of the ESTHER cohort. XZ C, B S, FA C, H C and Y Z analyzed. XZ C, B S and FA C wrote the paper. $\mathrm{H}$ B provided academic inspection.

\section{CONFLICTS OF INTEREST}

None declared.

\section{REFERENCES}

1. World Health Organization, International Agency for Research on Cancer. IARC monographs on the evaluation of carcinogenic risks to humans: schistosomes, liver lukes, and Helicobacter pylori. vol. 61. Lyon: IARC, 1994.
2. Venerito M, Selgrad M, Malfertheiner P. Helicobacter pylori: gastric cancer and extragastric malignancies clinical aspects. Helicobacter. 2013; 18 Suppl 1:39-43.

3. Sonnenberg A, Genta RM. Helicobacter pylori is a risk factor for colonic neoplasms. Am J Gastroenterol. 2013; 108:208-15.

4. Risch HA, Lu L, Kidd MS, Wang J, Zhang W, Ni Q, Gao YT, $\mathrm{Yu}$ H. Helicobacter pylori seropositivities and risk of pancreatic carcinoma. Cancer Epidemiol Biomarkers Prev. $2014 ; 23: 172-8$.

5. Plummer M. Helicobacter pylori and colonic neoplasms. Am J Gastroenterol. 2013; 108:216-7.

6. Xiao M, Wang Y, Gao Y. Association between Helicobacter pylori infection and pancreatic cancer development: a metaanalysis. PLoS One. 2013; 8:e75559.

7. Weck MN, Brenner H. Association of Helicobacter pylori infection with chronic atrophic gastritis: Meta-analyses according to type of disease definition. Int J Cancer. 2008; 123:874-81.

8. Zhang ZF, Kurtz RC, Klimstra DS, Yu GP, Sun M, Harlap S, Marshall JR. Helicobacter pylori infection on the risk of stomach cancer and chronic atrophic gastritis. Cancer Detect Prev. 1999; 23:357-67.

9. Weck MN, Gao L, Brenner H. Helicobacter pylori infection and chronic atrophic gastritis: associations according to severity of disease. Epidemiology. 2009; 20:569-74.

10. Malfertheiner P, Megraud F, O'Morain CA, Atherton J, Axon AT, Bazzoli F, Gensini GF, Gisbert JP, Graham DY, Rokkas T, El-Omar EM, Kuipers EJ, European Helicobacter Study Group. Management of Helicobacter pylori infection-the Maastricht IV/ Florence Consensus Report. Gut. 2012; 61:646-64.

11. Song H, Michel A, Nyren O, Ekstrom AM, Pawlita M, Ye W. A CagA-independent cluster of antigens related to the risk of noncardia gastric cancer: associations between Helicobacter pylori antibodies and gastric adenocarcinoma explored by multiplex serology. Int J Cancer. 2014; 134:2942-50.

12. Matos JI, de Sousa HA, Marcos-Pinto R, Dinis-Ribeiro M. Helicobacter pylori CagA and VacA genotypes and gastric phenotype: a meta-analysis. Eur J Gastroenterol Hepatol. 2013; 25:1431-41.

13. Yoshida $\mathrm{T}$, Kato J, Inoue I, Yoshimura N, Deguchi $\mathrm{H}$, Mukoubayashi C, Oka M, Watanabe M, Enomoto S, Niwa T, Maekita T, Iguchi M, Tamai H, et al. Cancer development based on chronic active gastritis and resulting gastric atrophy as assessed by serum levels of pepsinogen and Helicobacter pylori antibody titer. Int J Cancer. 2014; 134:1445-57.

14. Watabe H, Mitsushima T, Yamaji Y, Okamoto M, Wada R, Kokubo T, Doi H, Yoshida H, Kawabe T, Omata M. Predicting the development of gastric cancer from combining Helicobacter pylori antibodies and serum 
pepsinogen status: a prospective endoscopic cohort study. Gut. 2005; 54:764-8.

15. Kim N, Park RY, Cho SI, Lim SH, Lee KH, Lee W, Kang HM, Lee HS, Jung HC, Song IS. Helicobacter pylori infection and development of gastric cancer in Korea: long-term follow-up. J Clin Gastroenterol. 2008; 42:448-54.

16. Kamangar F, Qiao YL, Blaser MJ, Sun XD, Katki H, Fan JH, Perez-Perez GI, Abnet CC, Zhao P, Mark SD, Taylor PR, Dawsey SM. Helicobacter pylori and oesophageal and gastric cancers in a prospective study in China. $\mathrm{Br} \mathrm{J}$ Cancer. 2007; 96:172-6.

17. Gonzalez CA, Megraud F, Buissonniere A, Lujan Barroso L, Agudo A, Duell EJ, Boutron-Ruault MC, Clavel-Chapelon F, Palli D, Krogh V, Mattiello A, Tumino R, Sacerdote C, et al. Helicobacter pylori infection assessed by ELISA and by immunoblot and noncardia gastric cancer risk in a prospective study: the Eurgast-EPIC project. Ann Oncol. 2012; 23:1320-4

18. Kamangar F, Dawsey SM, Blaser MJ, Perez-Perez GI, Pietinen P, Newschaffer CJ, Abnet CC, Albanes D, Virtamo J, Taylor PR. Opposing risks of gastric cardia and noncardia gastric adenocarcinomas associated with Helicobacter pylori seropositivity. J Natl Cancer Inst. 2006; 98:1445-52.

19. Siman JH, Forsgren A, Berglund G, Floren CH. Association between Helicobacter pylori and gastric carcinoma in the city of Malmo, Sweden. A prospective study. Scand J Gastroenterol. 1997; 32:1215-21.

20. Cavaleiro-Pinto $M$, Peleteiro B, Lunet N, Barros $H$. Helicobacter pylori infection and gastric cardia cancer: systematic review and meta-analysis. Cancer Causes Control. 2011; 22:375-87.

21. Epplein M, Zheng W, Xiang YB, Peek RM Jr, Li H, Correa P, Gao J, Michel A, Pawlita M, Cai Q, Shu XO. Prospective study of Helicobacter pylori biomarkers for gastric cancer risk among Chinese men. Cancer Epidemiol Biomarkers Prev. 2012; 21:2185-92.

22. Shiota S, Murakami K, Okimoto T, Kodama M, Yamaoka Y. Serum Helicobacter pylori CagA antibody titer as a useful marker for advanced inflammation in the stomach in Japan. J Gastroenterol Hepatol. 2014; 29:67-73.

23. Ohata H, Kitauchi S, Yoshimura N, Mugitani K, Iwane M, Nakamura H, Yoshikawa A, Yanaoka K, Arii K, Tamai H, Shimizu Y, Takeshita T, Mohara O, et al. Progression of chronic atrophic gastritis associated with Helicobacter pylori infection increases risk of gastric cancer. Int J Cancer. 2004; 109:138-43.

24. Adamu MA, Weck MN, Rothenbacher D, Brenner H. Incidence and risk factors for the development of chronic atrophic gastritis: five year follow-up of a population-based cohort study. Int J Cancer. 2011; 128:1652-8.

25. Ma JL, Zhang L, Brown LM, Li JY, Shen L, Pan KF, Liu WD, Hu Y, Han ZX, Crystal-Mansour S, Pee D, Blot WJ, Fraumeni JF Jr, et al. Fifteen-year effects of Helicobacter pylori, garlic, and vitamin treatments on gastric cancer incidence and mortality. J Natl Cancer Inst. 2012; 104: 488-92.

26. Wong BC, Lam SK, Wong WM, Chen JS, Zheng TT, Feng RE, Lai KC, Hu WH, Yuen ST, Leung SY, Fong DY, Ho J, Ching CK, et al. Helicobacter pylori eradication to prevent gastric cancer in a high-risk region of China: a randomized controlled trial. JAMA. 2004; 291:187-94.

27. Ford AC, Forman D, Hunt RH, Yuan Y, Moayyedi P. Helicobacter pylori eradication therapy to prevent gastric cancer in healthy asymptomatic infected individuals: systematic review and meta-analysis of randomised controlled trials. BMJ. 2014; 348:g3174.

28. de Vries AC, Kuipers EJ. Epidemiology of premalignant gastric lesions: implications for the development of screening and surveillance strategies. Helicobacter. 2007; 12:22-31.

29. Dinis-Ribeiro M, Areia M, de Vries AC, Marcos-Pinto R, Monteiro-Soares M, O'Connor A, Pereira C, PimentelNunes P, Correia R, Ensari A, Dumonceau JM, Machado JC, Macedo G, et al. Management of precancerous conditions and lesions in the stomach (MAPS): guideline from the European Society of Gastrointestinal Endoscopy (ESGE), European Helicobacter Study Group (EHSG), European Society of Pathology (ESP), and the Sociedade Portuguesa de Endoscopia Digestiva (SPED). Endoscopy. 2012; 44:74-94.

30. Choi IJ. Current evidence of effects of Helicobacter pylori eradication on prevention of gastric cancer. Korean J Intern Med. 2013; 28:525-37.

31. Harris RA, Owens DK, Witherell H, Parsonnet J. Helicobacter pylori and gastric cancer: what are the benefits of screening only for the CagA phenotype of $\mathrm{H}$. pylori? Helicobacter. 1999; 4:69-76.

32. Pasechnikov V, Chukov S, Fedorov E, Kikuste I, Leja M. Gastric cancer: prevention, screening and early diagnosis. World J Gastroenterol. 2014; 20:13842-62.

33. Rokkas T, Sechopoulos P, Pistiolas D, Kothonas F, Margantinis G, Koukoulis G. The relationship of Helicobacter pylori infection and colon neoplasia, on the basis of meta-analysis. Eur J Gastroenterol Hepatol. 2013; 25:1286-94.

34. Thorburn CM, Friedman GD, Dickinson CJ, Vogelman JH, Orentreich N, Parsonnet J. Gastrin and colorectal cancer: a prospective study. Gastroenterology. 1998; 115:275-80.

35. Limburg PJ, Stolzenberg-Solomon RZ, Colbert LH, PerezPerez GI, Blaser MJ, Taylor PR, Virtamo J, Albanes D. Helicobacter pylori seropositivity and colorectal cancer risk: a prospective study of male smokers. Cancer Epidemiol Biomarkers Prev. 2002; 11:1095-9.

36. Robertson DJ, Sandler RS, Ahnen DJ, Greenberg ER, Mott LA, Cole BF, Baron JA. Gastrin, Helicobacter pylori, and colorectal adenomas. Clin Gastroenterol Hepatol. 2009; 7:163-7. 
37. Lindkvist B, Johansen D, Borgstrom A, Manjer J. A prospective study of Helicobacter pylori in relation to the risk for pancreatic cancer. BMC Cancer. 2008; 8:321.

38. de Martel C, Llosa AE, Friedman GD, Vogelman JH, Orentreich N, Stolzenberg-Solomon RZ, Parsonnet J. Helicobacter pylori infection and development of pancreatic cancer. Cancer Epidemiol Biomarkers Prev. 2008; 17: 1188-94.

39. Stolzenberg-Solomon RZ, Blaser MJ, Limburg PJ, PerezPerez G, Taylor PR, Virtamo J, Albanes D, Study A. Helicobacter pylori seropositivity as a risk factor for pancreatic cancer. J Natl Cancer Inst. 2001; 93:937-41.

40. Chen XZ, Wang R, Chen HN, Hu JK. Cytotoxin-associated gene A-negative strains of Helicobacter pylori as a potential risk factor of pancreatic cancer: A meta-analysis based on nested case-control studies. Pancreas. 2015; 44:1340-4.

41. Gao L, Weck MN, Michel A, Pawlita M, Brenner H. Association between chronic atrophic gastritis and serum antibodies to 15 Helicobacter pylori proteins measured by multiplex serology. Cancer Res. 2009; 69:2973-80.

42. Gao L, Michel A, Weck MN, Arndt V, Pawlita M, Brenner H. Helicobacter pylori infection and gastric cancer risk: evaluation of $15 \mathrm{H}$. pylori proteins determined by novel multiplex serology. Cancer Res. 2009; 69:6164-70.

43. Epplein M, Pawlita M, Michel A, Peek RM Jr, Cai Q, Blot WJ. Helicobacter pylori protein-specific antibodies and risk of colorectal cancer. Cancer Epidemiol Biomarkers Prev. 2013; 22:1964-74.
44. Brenner H, Rothenbacher D, Weck MN. Epidemiologic findings on serologically defined chronic atrophic gastritis strongly depend on the choice of the cutoff-value. Int $\mathrm{J}$ Cancer. 2007; 121:2782-6.

45. Schöttker B, Adamu MA, Weck MN, Brenner $H$. Helicobacter pylori infection is strongly associated with gastric and duodenal ulcers in a large prospective study. Clin Gastroenterol Hepatol. 2012; 10:487-93 e1.

46. Saum KU, Dieffenbach AK, Müller H, Holleczek B, Hauer K, Brenner H. Frailty prevalence and 10-year survival in community-dwelling older adults: results from the ESTHER cohort study. Eur J Epidemiol. 2014; 29:171-9.

47. Weck MN, Brenner H. Prevalence of chronic atrophic gastritis in different parts of the world. Cancer Epidemiol Biomarkers Prev. 2006; 15:1083-94.

48. Zhang Y, Weck MN, Schöttker B, Rothenbacher D, Brenner H. Gastric parietal cell antibodies, Helicobacter pylori infection, and chronic atrophic gastritis: evidence from a large population-based study in Germany. Cancer Epidemiol Biomarkers Prev. 2013; 22:821-6.

49. Chen Y, Segers S, Blaser MJ. Association between Helicobacter pylori and mortality in the NHANES III study. Gut. 2013; 62:1262-9. 